\title{
Design and Implementation of Cascade Fuzzy Controller For Secondary Pipe Network Of Heat Exchange Station
}

\author{
Hai Tian ${ }^{1 *}$, Zhenkui $\mathrm{Wu}^{1}$ and Xiaojun $\mathrm{Qi}^{2}$ \\ ${ }^{1}$ Information Engineering College, Inner Mongolia University of Science and \\ Technology, Baotou 014010, China \\ ${ }^{2}$ Department of Automation, Baotou Iron and Steel Technical College, Baotou \\ 014010, China \\ *E-mail:btwx548548@sohu.com
}

\begin{abstract}
In view of problems of obtaining and tracking given value of the supply water temperature of secondary network in central heating system, a fuzzy control strategy composed of fuzzy control and fuzzy parameter self-tuning PID in series was proposed. For a specific project, a monitoring and control system formed of wired and wireless network was built to meet the overall monitoring requirement of system. Total scheme of the network structure, control strategies, as well as system configuration and realization methods of the related process were designed. Meanwhile, Simulation experiments on the MATLAB/SIMULINK software platform of the cascade fuzzy controller were also designed in detail. In order to improve reliability and real-time performance of the control, the cascade fuzzy controller was realized on Siemens S7-200PLC. The simulation results and practical effect both show that the cascade fuzzy controller has good dynamic performance and robustness. Design of the monitoring and control system based on control network comprehensively improves the human-computer interaction ability, as well as management and automatic control level.
\end{abstract}

Keywords: obtaining and tracking given value, supply water temperature, central heating system, monitoring and control system, cascade fuzzy controller, control network

\section{Introduction}

In the north of China, the usually adopted heating system of the urban residents was separate and decentralized coal-fired boiler system. Moreover, coal-burning pollution influenced the residents seriously. Because automation control and management level of the system were not high, the overall efficiency was low. In conditional region, the traditional way of coal-fired boiler heating system is gradually being replaced by urban centralized heat supplying system. At present, some problems have become the focus of central heating field, such as how to reasonably adjust all operation parameters of the urban centralized heat supplying system, how to use advanced means of communication for real-time monitoring and scheduling of important thermal parameters, and how to improve the quality of automatic control and management level to provide quality service to the user. A district residents early adopted separate coal-fired boiler heating system, with promoting of development plan of urban central heating, the separate coal-fired boiler heating system needed to be converted to a lower heat exchange station [1].

In the previous lower heat exchange station of central heating system, the temperature adjustment method and the temperature curve compensation method were adopted for given value acquisition of the secondary network water supply temperature. 
The temperature adjustment method presented in reference[2] can be understood as: under the condition of system stability, the heat energy users of the secondary pipe network should be equivalent to a heat sink firstly, and according to the function relationship among supplied heat of the heating system, the heat release of the radiating system and the heat consumption of heat energy users, the function relation between the supply water temperature of the secondary pipe network and the outdoor temperature as well as indoor temperature is got. Secondly, assuming that the indoor temperature is constant ( at $18{ }^{\circ} \mathrm{C}$ normally, appropriate to users) and water supply temperature of the secondary pipe network approximates to the setting value, the function relationship will be modified and fitted according to the regular climate change data of the heating network area and actual heating parameters. Relation curve between supply water temperature given value of the secondary pipe network and the outdoor temperature is finally determined. The shortage of this method is it is difficult to establish precise mathematical model. For example, influence of uncertain factors like extreme changes in weather conditions can not be taken into consideration, and during the process of curve fitting and correction, bigger errors tend to be produced so the actual control effect is not ideal.

The method of temperature curve compensation involved in reference [3] can be explained as: according to the local meteorological data and characteristic parameters of the heating object, the designer can set and revise the function curve between the water supply temperature given values of the secondary pipe network and the outdoor temperature in advance. Then according to the actual outdoor temperature, the given value of the secondary pipe network water temperature can be found corresponding to the fixed relation curve. The shortcoming of this way is that it can only indicate experience relationship between outdoor temperature and given value of the secondary network water supply temperature, but not reflect influence of the outdoor temperature change on the given value, so the effect is not good.

The common disadvantage of the above two methods is that the water supply temperature setting value of the secondary pipe network is not considered to be an uncertain and random fuzzy variables, and it's difficult to be accurately expressed by conventional mathematical model or function relation.

In the previous lower heat exchange station of central heating system, conventional PID (proportion integration differentiation) control strategy was adopted for tracing method of supply water temperature given value of the secondary network. Supply water temperature closed loop control method pointed out in reference [4] can be explained as: the secondary pipe network water temperature set point is compared with the actual temperature feedback value, and output of PID controller is used to adjust the opening of supply water electric valve of the primary pipe network, then water temperature set point of the secondary pipe network is traced by regulating the flow of the primary pipe network. But in this method, nonlinear and time-varying of the controlled object are not considered.

Based on previous researches, a compound controller formed by series connection of conventional fuzzy controller and fuzzy PID controller was designed to obtain and track the supply water temperature given value dynamically.

\section{Control Strategy of the Lower Heat Exchange Station}

The control process of the central heating system is shown in Figure 1. 


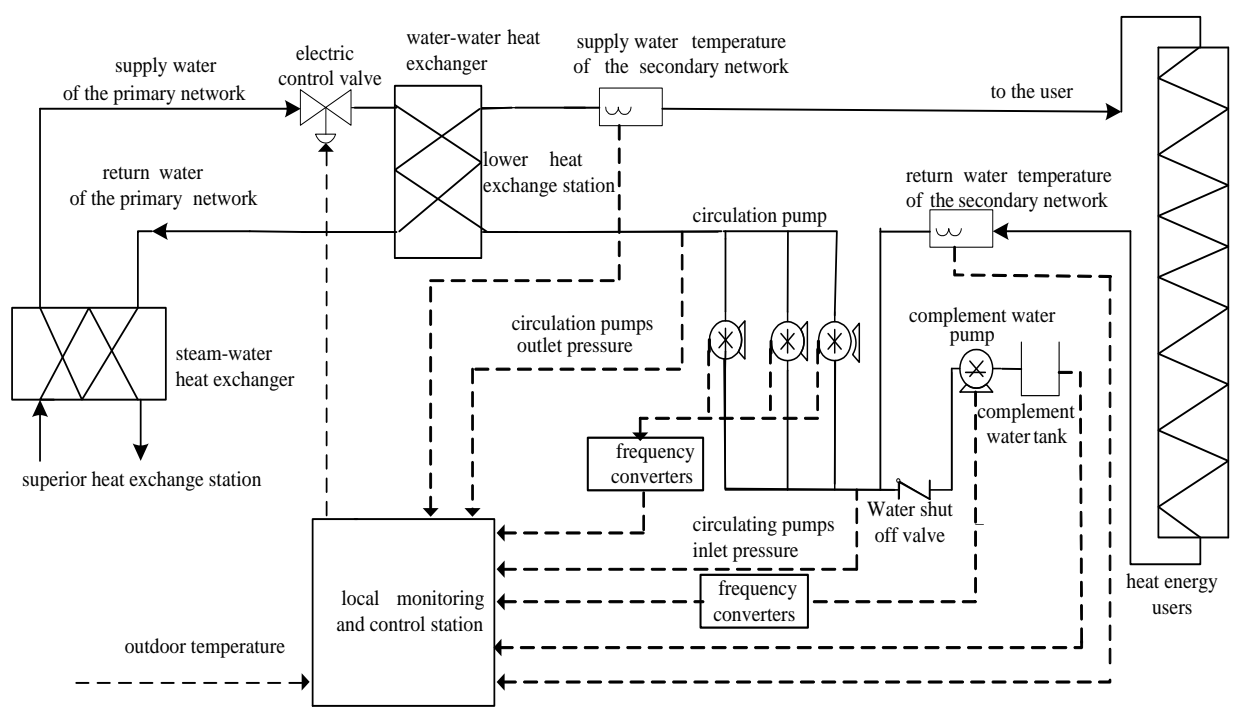

Figure 1. Control Process Diagram of the Central Heating System

High temperature steam produced by a thermal power plant or a heat source plant will be transformed into high temperature water by a steam - water exchanger in the superior exchange station of the central heating system, and the high temperature water is delivered to a primary pipe network of water-water exchanger in the lower exchange station of the central heating system, then the exchanged high temperature water is delivered to users by the circulation water pumps of secondary network system in the lower heat exchange station. Water loss of the secondary network of the lower heat exchange station will be compensated by the compensation water pumps of the secondary network system at the entrance of circulation water pumps.

Based on excellent control quality of the fuzzy control strategy for time-varying and nonlinear systems [5], a cascade fuzzy controller was put forward to acquire and track supply water temperature given value of the secondary network in the lower heat exchange station. The former controller of the cascade fuzzy controller is a conventional fuzzy controller of two inputs and one output, the outdoor temperature and change of the outdoor temperature are taken as inputs of the former conventional fuzzy controller; the output value of the former controller is supply water temperature given value of the secondary network; and this output value will be one input value of the latter fuzzy PID controller.

The latter fuzzy controller of the cascade controller is a fuzzy PID controller, and it is a combination of fuzzy inference and traditional PID. Supply water temperature set point got from the former controller is compared with the actual temperature value of supply water, then both of the temperature difference and the temperature difference change rate $e c$ will be taken as two inputs values of the fuzzy inference part. The $\mathrm{K}_{\mathrm{P}}, \mathrm{K}_{\mathrm{I}}$ and $\mathrm{K}_{\mathrm{D}}$ parameters of the conventional PID controller are corrected by using the output values of fuzzy reasoning parameters calibration $\triangle K_{P}, \triangle K_{I}$ and $\triangle K_{D}$. The traditional PID output value is used to adjust the openings of the primary network electric valve of lower heat exchange station. By adjusting the supply water flow of the primary network of lower heat exchange station, the supply water temperature of the secondary network of lower heat exchange station is kept steady on the given value [6]. The cascade fuzzy controller block diagram is shown in figure 2 . 


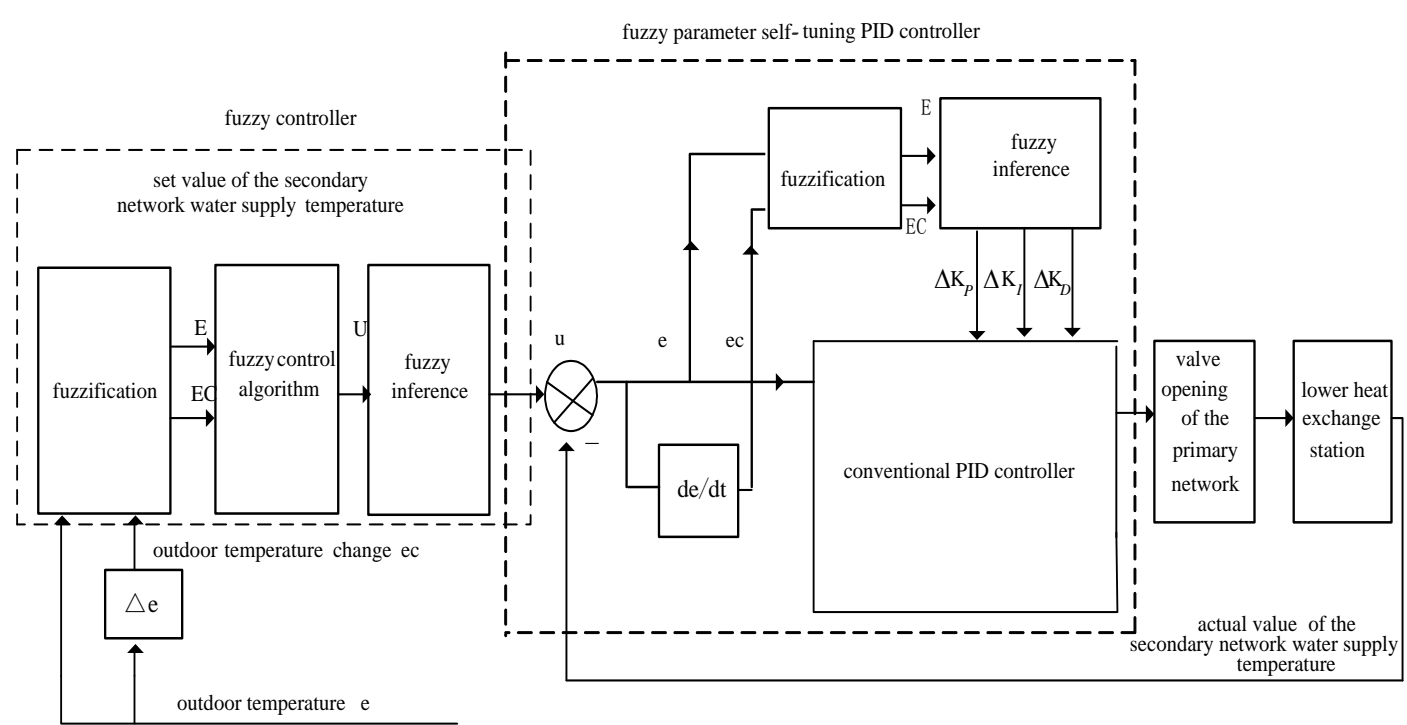

Figure 2. Block Diagram Of The Cascade Fuzzy Controller

A central heating system is a complex system engineering, which is associated with many problems. The control strategy of this design mainly aims at improvement of the acquisition and tracking method of supply water temperature setting values of the secondary pipe network in a lower heat exchange station. It is a core technology problem concerning central heating system. Two other important processes associated with the cascade fuzzy controller of the secondary network water supply temperature are the complement water system and circulatory water system.

Function of the circulatory water system of the secondary pipe network is to transfer heat of the secondary pipe network to heat energy users in time, and the heat is exchanged from the flat plate heat exchanger to the secondary pipe network. Through regulating effect of the compound controller, the supply water temperature of the secondary network of lower heat exchange station is on the given value. If the temperature difference between supply and return water of the secondary pipe network increases, it means that heat consumption of heat users is bigger, and the cycle pump system need to input more power to meet the actual needs of heat users and ensure indoor temperature within a reasonable range; otherwise, it means heat consumption is smaller, and the cycle pump system need to input less power to avoid unnecessary waste of energy.

To save energy, a reasonable temperature difference control strategy between supply water and return water should be set. So in the circulatory water system of the secondary network of lower heat exchange station, a variable frequency PID controller of constant temperature difference is adopted for the supply water and return water temperature difference control; but in the filling water system of the secondary pipe network, the variable frequency PID control method of constant water pressure is adopted.

\section{Control Network Structure and System Configuration}

Realization of the cascade fuzzy control strategy depends on the control network. The function of the complement water system PID controller and the circulation water system PID controller is also realized by making use of the control network. During the design of the heat exchange station monitoring system, a local monitoring and control station based on industrial field bus is set up. Functions like monitoring, archiving and analyzation of the thermal parameters of the lower heat exchange station are all done locally, as well as automatic control of a variety of thermal process. To monitor the running status of the 
lower heat exchange station conveniently, a remote monitoring center is set up in the remote central heating center [7]. It can also optimize heat resource scheduling and improve automation management level. Since the remote monitoring and control center is far from the local monitoring and control station, and installation of wired cable is expensive, the GPRS (general packet radio service) wireless communication is used between the remote and local stations. The whole monitoring and control system includes a wireless remote monitoring center, a GPRS wireless network and a local monitoring and control station.

Network structure diagram of the monitoring and control system is shown in Figure 3.

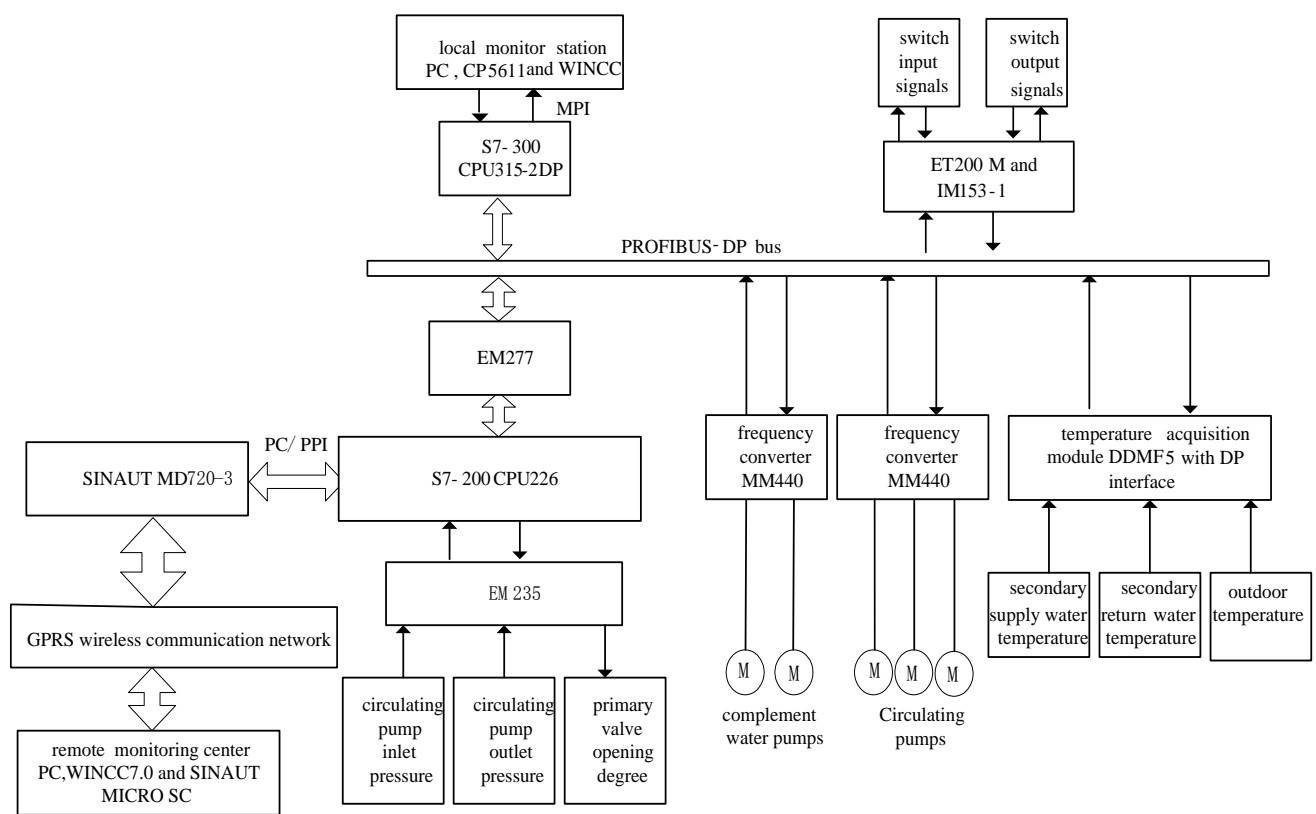

Figure 3. Network Structure Diagram of the Monitoring System

(1) The local monitoring and control station is composed of four kinds of PROFIBUSDP slave stations and two kinds of PROFIBUS-DP master stations; the PROFIBUS-DP field bus is adopted for communication between the slave stations and the master stations.

There are four kinds of PROFIBUS-DP slave stations. The first kind of PROFIBUSDP slave station is composed of EM227 module+ EM235 module+S7-200CPU226 PLC (programmable logic controller). In order to enhance the real-time control, the cascade fuzzy controller of the supply water temperature of the secondary network is directly constructed on the S7-200CPU226PLC. The special module SINAUT MD 720-3 for GPRS wireless communication is installed on the S7-200CPU226 PLC and can communicate with S7-200 CPU226PLC for receiving and sending data via PPI cable (Siemens order no. : 6ES7901-3CB30-0XA099). The S7-200CPU226 PLC is connected to the PROFIBUS-DP field bus via the special EM227 module of the PROFIBUS-DP slave station.

The second kind of PROFIBUS-DP slave station is composed of Siemens frequency converters MM440 with special PROFIBUS-DP communication card CBP2, which are used as driving devices of the filling water motors and the circulating water motors.

The third kind of PROFIBUS-DP slave station is composed of temperature collection DDMF5 module with PROFIBUS-DP interface, used for acquisition of the outdoor actual temperature, the supply water actual temperature and the backwater actual temperature of the secondary network. Among them, the supply water actual temperature of the secondary pipe network and the outdoor actual temperature are used in the calculation of the cascade fuzzy controller, and difference between supply water and return water actual 
temperature of the secondary pipe network is used as feedback of the constant temperature difference variable frequency PID controller in the circulatory water system.

The fourth kind of PROFIBUS-DP slave station is composed of remote I/O station ( IM153-1 module+ ET200M module).

The S7-300CPU315-2DP PLC is adopted as the first kind of PROFIBUS-DP master station. In the PC of the second kind of PROFIBUS-DP master station, monitoring software WINCC7.0, STEP7V5.5 programming software and the communication module CP5611 are installed. Functions like test and control are achieved in real time on the first type master station. Other functions are achieved on the second type master station, for example, real time data configuration, function setting, data archiving, report printing, content query, fault diagnosis and alarming.

(2) In the current industrial control field, the major methods of PLC remote wireless communication are radio modem, GPRS, and wireless Ethernet [8]. The radio modem communicates via dedicated ultrashort wave data channel, so it's a special data network, and it has some main advantages, such as high safe data transmission, flexible networking, the low construction cost. But the main drawbacks include: the signal is easily affected by terrain and high-rise buildings, so it's not suitable to be used in the city; moreover, coverage of the network signal is small. The advantages of wireless Ethernet include: fast data communication, good real-time performance, and high accuracy. But the fatal flaw is the network signal coverage is small, generally less than $1 \mathrm{~km}$.

The data communication technology of global mobile communication system is used in GPRS system, so it can make full use of public network resources and provides a wide range of data services for the users living in the area which is covered by network signal. So it has some advantages like wide signal coverage, strong durability, high performance price ratio, and mature technical support. But it should not be used in the wireless communication applications where high safety and real-time performance are required. The main functions of the remote monitoring center include monitoring, archiving and scheduling of the process parameters of the distributed heat exchanger stations, so it doesn't require the data communication to be high real-time. After comprehensive comparison, the GPRS is adopted in the monitoring and control system.

(3) OPC(object linking and embedding for process control) routing software SINAUT MICRO SC and monitoring software WINCC7.0 are installed on the PC of the central heating center. To improve data and information security through the public network, the public internet is connected to the remote monitoring and control center $\mathrm{PC}$ via the internal LAN firewall devices. The routing software OPC realizes the data and information routing functions between the public internet and the GPRS wireless communication network. The monitoring software WinCC7.0 can easily read a variety of process data of the lower heat exchange station, which are integrated to the public internet by the SINAUT MICRO SC routing software.

\section{Design and Realization of System Functions}

\subsection{Design of the Compound Cascade Fuzzy Controller}

Design methods of the former fuzzy controller are as follows. Constructing of the latter fuzzy PID controller is similar to that of the former controller, so it is not discussed.

(1) Fuzzy output and input values of the former fuzzy controller: the basic theory domain of the supply water temperature given value $u$ is set to $\left[15^{\circ} \mathrm{C}, 75^{\circ} \mathrm{C}\right]$; the basic theory domain of the outside temperature $e$ is set to $\left[-30^{\circ} \mathrm{C},+20^{\circ} \mathrm{C}\right]$; the basic theory domain of the outside temperature change $e c$ is set to $\left[-8^{\circ} \mathrm{C},+8^{\circ} \mathrm{C}\right]$. Triangle curve is selected as the membership function curve for each variable $u, e$ and $e c$. Fuzzy theory 
domain for each of the three variables $u, e$ and $e c$ is set to $[-6,+6]$, and seven fuzzy subset $\{$ NB NM NS ZO PS PM PB $\}$ are selected for each variable $u, e$ and $e c$.

(2) Obtaining of fuzzy control rules of the former fuzzy controller: fuzzy rules contain plentiful experiences of people, so they decide the control performance of the fuzzy controller [9]. Combined with the operation experiences, the fuzzy control rules of the former fuzzy controller are as shown in table 1.

Table 1. The Fuzzy Control Rules of the Former Fuzzy Controller

\begin{tabular}{|l|l|l|l|l|l|l|l|}
\hline$E C / E$ & NB & NM & NS & ZO & PS & PM & PB \\
\hline NB & NB & NB & PM & ZO & ZO & ZO & PB \\
\hline NM & NB & NB & NM & ZO & ZO & ZO & NB \\
\hline NS & NB & NB & NB & ZO & ZO & PS & NB \\
\hline ZO & NB & NB & ZO & ZO & PB & PM & NB \\
\hline PS & NB & NS & PS & ZO & PM & PB & NB \\
\hline PM & NB & ZO & PS & ZO & PM & PB & PB \\
\hline PB & NB & ZO & ZO & ZO & PB & PB & PB \\
\hline
\end{tabular}

(3) Clarifications of the output values of the former fuzzy controller: the main methods of defuzzification include the maximum membership degree method, the gravity method and the median method. The output values of the former fuzzy controller need to be defuzzificated [10]. The gravity defuzzification method is adopted for the former fuzzy controller of the cascade fuzzy controller.

\subsection{PLC Realization of the Compound Cascade Fuzzy Controller}

Firstly the two query tables of the two-stage fuzzy controllers are acquired by making use of the simulation software MATLAB, which are the output results of the former and latter fuzzy controller, then the two query tables are stored in the data storage V of the PLC. During the control process, the S7-200CPU226 PLC directly gets the output results of the former and latter controllers, according to the input values of the former and latter controllers [11].

Taking the latter fuzzy PID controller as an example, the PLC inputs the temperature difference change rate $e c$ and the temperature difference $e$ of the secondary network supply water temperature into the latter-stage fuzzy parameter self-tuning PID controller. Then the PLC acquires fuzzy inference output parameters $\triangle K_{P}, \triangle K_{I}$ and $\triangle K_{D}$ from the query table of the latter fuzzy PID controller, and these parameters are compensation values needed by $K_{P}, K_{I}$ and $K_{D}$ parameters of the conventional PID controller. After correction, the $\mathrm{K}_{\mathrm{P}}, \mathrm{K}_{\mathrm{I}}$ and $\mathrm{K}_{\mathrm{D}}$ parameters are assigned to the conventional PID controller to control the openings of the primary pipe network electric valve of lower heat exchange station. The software PID module in the PLC is adopted for the conventional PID controller of the latter fuzzy PID controller.

\subsection{PLC Realization of Circulation and Complement Water Systems}

(1) In order to enhance the reliability and real-time control of system, the software PID modules of the S7-200CPU226 PLC is adopted to realize the constant temperature difference variable frequency PID controller of the secondary pipe network supply and return water. The given temperature difference of the PID controller can be set directly in 
the PID module. Temperature difference feedback of the PID controller is got from the difference between supply and return water temperatures, which are collected by the temperature acquisition module DDMF5 and compared in the S7-200CPU226 PLC. Output of the PID controller is taken as speed given signal of the variable frequency motors of the circulation system. The S7-200CPU226 PLC undertakes the logic control task for the three circulating pump motors at the same time. In order to prevent the pumps to rust for no starting for a long time and balance the using probability of the three circulating pumps, the circulating control strategy of first start and first stop will be adopted for the logic control, and the circulating pump motors will also be changed regularly.

(2) The constant water pressure variable frequency PID controller adopted by the secondary pipe network is realized by the PID module in the S7-200CPU226 PLC. There are two complement pumps, one for spare and one for use.

Access points (hydrating point) from the complement pump to the secondary pipe network is at the entrance of the circulating pump. Because of the suction effect after start-up of the circulation pump, pressure at the entrance of the circulating pump group is the lowest, and pressure at the exit is the highest. So complement water at the entrance of the three circulating pumps can reduce the actual input power of the complement motor, and the energy saving effect is obvious. When the three circulating pumps are working normally, outlet and inlet pressures of them are also changing, due to switching of the circulating pump motors and speed change during the process of dynamic adjustment. So the water pressure feedback for one point can not represent the average pressure of the secondary pipe network. The inlet and outlet water pressures are both collected by the EM235 analog I/O expansion modules of the S7-200CPU226 PLC, then the values are averaged in the PLC and taken as the feedback of the constant pressure variable frequency PID controller for complement water system.

The setting value of water pressure of the secondary pipe network is directly set by the software in the PID module. Output of the PID controller is taken as the speed given signal for the variable frequency motors of the complement water system.

\subsection{Simulation Experiments and Running Effect}

Taking the latter-stage fuzzy PID controller as an example: to verify advantages of the dynamic adjustment and the effectiveness of the control, both of the fuzzy PID controller and the conventional PID controller are simulated by making use of the SIMULINK software platform in the MATLAB.

For the two algorithms of the fuzzy PID control and the conventional PID control, the same mathematical model is built on SIMULINK software platform in the MATLAB for the controlled object [12]. Assume that the outdoor actual temperature decreases quickly and supply water temperature given value suddenly rises from $55^{\circ} \mathrm{C}$ to $60{ }^{\circ} \mathrm{C}$. The simulation waveform figure of the fuzzy PID for the supply water temperature of the secondary pipe network is shown in figure 4 , and the simulation waveform figure of the conventional PID for the supply water temperature of the secondary pipe network is shown in figure 5. In order to make the control achieves an ideal effect, the $K_{P}, K_{I}$ and $K_{D}$ initial parameters of the fuzzy PID control and the $K_{P}, K_{I}$ and $K_{D}$ fixed parameters of the conventional PID control are set by making use of the Ziegler-Nichols method. 


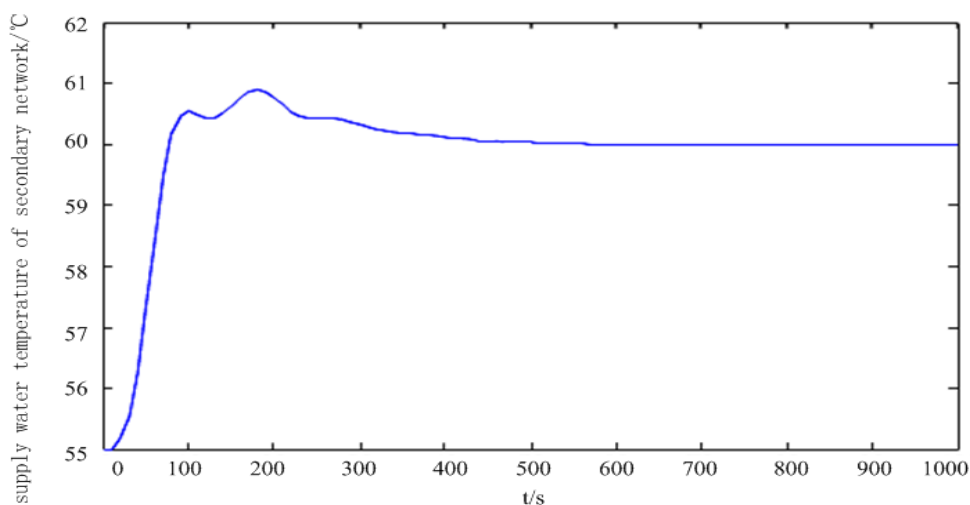

Figure 4. Simulation Waveform Figure of the Fuzzy PID Controller

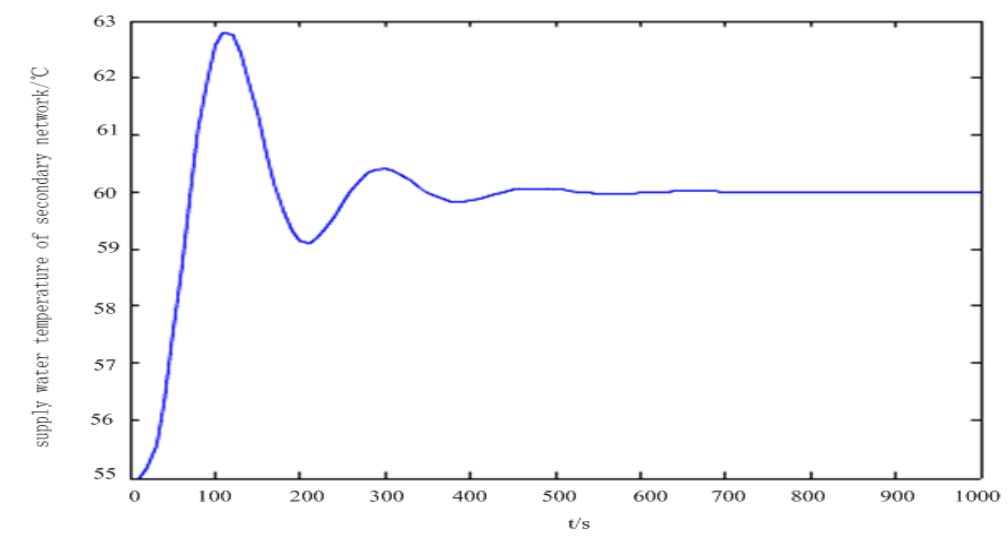

Figure 5. Simulation Waveform Figure of the Conventional PID Controller

The simulation results show that: the overshoot of the fuzzy PID control is less than the conventional PID control, and the dynamic adjusting speed of the fuzzy PID control is faster. So the fuzzy parameter self-tuning PID control is superior to the conventional PID control.

Because the temperature cascade fuzzy controller of the secondary network, the constant temperature difference variable frequency PID controller of the circulating system and the constant water pressure variable frequency PID controller of the water complement system are put into use cooperatively, the operation effect of the system is improved greatly, compared with the effect of the system before the transformation.

The indoor temperature of heat energy users is an important indicator of evaluating system. The local heating time period of the central heating system is started from November 10th of the year and ended on May 10th of the next year. The heating system is required to set the actual indoor temperature control index between $17{ }^{\circ} \mathrm{C}$ and $23{ }^{\circ} \mathrm{C}$. Because of the technological reform, the number of days up to standard has been improved from 105 days to 179 days, according to the operation records.

Before and after the technological renovation, the power configuration of the $3 \times 75 \mathrm{~kW}$ motors of the circulating system and the $2 \times 7.5 \mathrm{~kW}$ motors of the complement pump system remains the same. Before the technological renovation, all of the filling water motors and the circulating water motors adopted the power frequency running mode, so it was a waste of energy. After the technological reform, the variable frequency PID controller is adopted for the filling water motors and circulating water motors, so energy saving and consumption reducing effects are both obvious. According to the statistics of the administrative department, the power saving rate reaches $11.6 \%$ on the average and 
the monitoring and control system can help to save about $99500 \mathrm{~kW}$.h electric power in each year.

After each heating period, the management department would carry on a questionnaire investigation to the residents of the heating area. Statistical data showed that after the renovation, the heating comprehensive satisfaction of the residents rose from an average of $61.7 \%$ to $95.6 \%$.

\section{Conclusions}

After in-depth analysis and research of the problems of the current domestic and overseas methods of acquisition and tracking of secondary network water supply temperature given value, a new cascade fuzzy controller was constructed, because of excellent properties of fuzzy control for nonlinear and uncertain fuzzy variables. The control network system designed also in this project contains a local monitoring system based on PROFIBUS, a GPRS communication network and a remote monitoring center. Monitoring of all of the thermal parameters as well as automatic control of various thermal process of the lower heat exchange station have been realized in the local monitoring and control system. In the remote monitoring center, the running status of the lower heat exchange station can be monitored and scheduled to enable the heating center to manage and control simultaneously. The cascade fuzzy controller has improved control performance of the monitoring system, so it has high value for engineering application.

\section{Acknowledgements}

This research project was funded by the Natural Science Fundation of Inner Mongolia autonomous region, PR China (Project number: 2013MS0921).

\section{References}

[1] T. Liang, A. L. Ma, H. X. Sun and J. Zhang, "Development of automatic system of heat exchange station with GPRS module” , Electric Drive, Vol. 38, no. 7, (2008), pp. 69-72.

[2] H. Q. Zang and X. G. Li, "Drawing of temperature adjustment curve under centralized control with flow varied by steps”, Gas \& Heat, Vol. 28, no. 6, (2008), pp. 18-20.

[3] R. Burzynski, M. Crane, R. Yao and V. M. Becerra, "Space heating and hot water demand analysis of dwellings connected to district heating scheme in UK" , Journal of Central South University, no. 6, (2012), pp. 1629-1638.

[4] B. Jacimovic, B. Zivkovic, S. Genic and P. Zekonja, "Supply water temperature regulation problems in district heating network with both direct and indirect connection” , Energy and Buildings, Vol. 28, no. 3, (1998), pp. 317-322.

[5] X. Li, G. Lu, S. Li, Y. Zhou and Q. Li, “The design of wheeled robot controller based on fuzzy PID agorithm” , Small \& Special Electrical Machines, vol. 11, no. 5, (2011), pp. 57-60.

[6] Y. F. Wang and T. Y. Chai, "Present status and future development of adaptive fuzzy control" , Control Engineering of China, Vol. 13, no. 3, (2006), pp. 193-198.

[7] H. Tian, G. M. Cui, X. H. Wang and Y. C. Xue, "Control network configuration stratagem and application of SIMATIC PLC”, Electric Drive, Vol. 40, no. 1, (2010), pp. 76-80.

[8] Z. J. Liu, Y. M. Quan and L. Liang, “A wireless system for cutting temperature measurement," Advanced Materials Research, vol. 188, (2011), pp. 475-480.

[9] X. J. Lu and J. P. Li, "Research and simulation analysis of car following system based Fuzzy PID control” , Information Technology Journal, vol. 12, no. 23, (2013), pp. 7379-7384.

[10] E. M. Jafarov, M. N. A. Parlakci and Y. Istefanopulos, “A new variable structure PID-controller design for robot manipulators” , IEEE Transactions on Control Systems Technology, vol. 13, no. 1, (2005), pp. $122-130$.

[11] C. D. Jung, J. Mook, Kang and C. H. Park, "Study of engine oil replacement time estimate method using fuzzy and neural network algorithm in ubiquitous environment" , International Journal of Control and Automation (IJCA), vol. 6, no. 3, (2013), pp. 267-280.

[12] S. Skoczowski, S. Domek, K. Pietrusewicz and B. Broel-Plater, " A method for improving the robustness of PID control”, IEEE Transactions on Industrial Electronics, vol. 52, no. 6, (2005), pp. 1669-1676. 


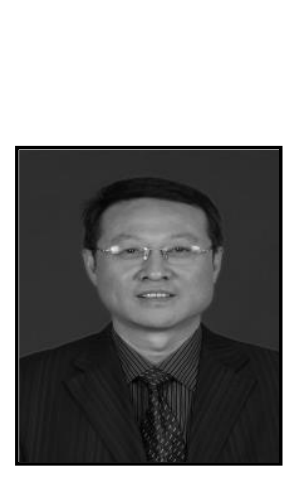

\begin{abstract}
Authors
Hai Tian received the bachelor's degree of electrical automation from Inner Mongolia university of science and technology, Baotou, PR China, in 1992 and the master's degree of control theory and control engineering from Beijing university of science and technology, Beijing, PR China, in 2002. He has been working in Inner Mongolia university of science and technology since 1992. He has been master's tutor since 2006 and associate professor since 2004. His research interests include electric drive, network control and intelligent control.
\end{abstract}

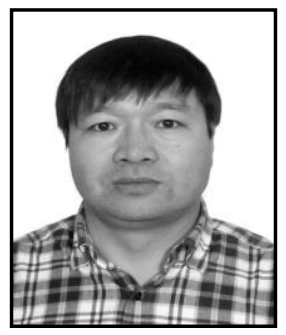

Zhenkui Wu received the bachelor's degree of electrical engineering from Inner Mongolia university of science and technology, Baotou, PR China, in 1995 and the doctor's degree of control theory and control engineering from Inner Mongolia university of technology, Huhehaote, PR China, in 2014. His research interests include network control and intelligent control.

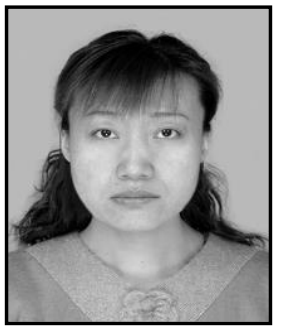

Xiaojun Qi received the bachelor's degree of electrical automation and master's degree of control engineering from Inner Mongolia university of science and technology, Baotou, PR China, in 1992 and 2008, respectively. Her research interests include measurement and control instrument, network control and new energy. 
International Journal of Control and Automation Vol.8, No.8 (2015) 